\title{
Structure and Behaviour of Chromosomes in Bauhinia and Allied Genera
}

\author{
Arun Kumar Sharma and D. Tulsi Raju \\ Cytogenetics Laboratory, Department of Botany, University of Calcutta, \\ 35, Ballygunj Circular Road, Calcutta 19, India
}

Received November 11, 1967

\section{Introduction}

The genera Bauhinia, Phanera and Piliostigma studied here, are included within the tribe Bauhinieae in the family Caesalpinaceae under De Wit's revised system of classification (1956). In the earlier system of Bentham and Hooker, all these three genera were included under Bauhinia within the monotype tribe Bauhinieae under the suborder Caesalpinieae of the order Leguminosae. The simple bilobed leaf-an outstanding character of this genus is principally responsible for its separate tribal status. This character is not only conspicuous but is universally present in all the species with slight variations in the extent of lobation. Taxonomically it is regarded as a uniform genus by all taxonomists, regarding it as a natural assemblage. The habit of the plants too is quite uniform, being mostly large or small trees.

From the point of view of cytology, the genus is remarkable as well in that most of the species are characterised by a uniform chromosome number of $2 \mathrm{n}=28$ (Atchison 1951, Miège 1960, Raghavan 1957, Turner 1956b, Turner and Irwin 1961 and Turner and Fearing 1959). Only in Bauhinia monandra, Poucques (1945) reported 42 chromosomes in the somatic cells, thus maintaining the same basic set of 14 chromosomes.

The importance of cytological study in solving the problems of taxonomic dispute as well as in tracing interrelationships, affinities and evolution of different taxa is well established. Not only the chromosome number but the detailed chromosome morphology as well are taken into serious consideration in such studies. In a number of cases such as in the genus Lilium (Stewart and Bamford 1943), etc., slight variations in chromosome morphology are associated with evolution even though the chromosome number in all the taxa is constant. Lately, the invention of a number of pre-treatment chemicals has considerably aided the study of chromosome morphology in detail (Sharma 1956a). With the aid of these methods, minute differences in the study of karyotype too can easily be detected. These three genera evidently provide an ideal material for such an investigation.

Cursory examinations of the somatic chromosomes of these genera indicated that the materials are not very favourable for such investigation especially due to the heavy cytoplasmic content and very small chromosomes. 
Evidently, this is the principal reason why it has been lying unexplored. After a series of trials in different chemicals a method has been standardized, with which the present investigation was carried out.

\section{Materials and methods}

The present cytological investigation was carried out on twenty-four species and varieties of the genera Bauhinia, Phanera and Piliostigma.

All of them have been collected from the Indian Botanical Gardens at Sibpur, Howrah and from Jamshedpur in Bihar.

Temporary orcein squash method has been found to be very suitable for the study of somatic chromosomes. Of different pre-treatment chemicals tried, isopsoralene was found to be the most effective one in producing wellscattered metaphase plates with clarified constrictions (Chaudhuri, Chakraborty and Sharma 1962). Healthy young root-tips were pretreated in saturated solution of isopsoralene for $2 \frac{1}{2}$ to 4 hours in cold $\left(9^{\circ} \mathrm{C}-10^{\circ} \mathrm{C}\right)$, fixed in propionic acid : ethyl alcohol $(1: 2)$ solution for about 45 minutes to an hour and stained by gently heating for a few seconds in a mixture of $2 \%$ aceto-orcein and $\mathrm{N}-\mathrm{HCl}$ solutions $(9: 1)$. They were kept as such for overnight and the tip portions were subsequently squashed in $1 \%$ aceto-orcein solution or $45 \%$ acetic acid on a slide by applying uniform pressure over the coverslip and blotting off the excess stain. The slides thus prepared were properly sealed and observed under the microscope.

The aceto-orcein squashes were made permanent by first removing the wax seal and then by inverting them in a petri-dish containing normal butyl alcohol till the coverslip was detached from the slide and were subsequently mounted in euparal.

For meiotic studies, both smear and permanent sections were prepared from flower buds. Anthers of suitable size were smeared and stained in 1\% propiono-carmine solution, after a long period (3-4 days) of fixation in propiono: alcohol $(1: 3)$. Preparations in propiono-carmine gave much better results than those with any other chemical.

Block preparations were also carried out as usual after the fixation of flower buds in Nawashin's fluids A and B $(1: 1)$ for overnight, following pre-treatment in Carnoy's fluid and washing in water. Sections were cut $14 \mu$ thick and stained following Newton's Crystal Violet Schedule. Mordanting in a mixture of 10\% acetic acid and 1\% chromic acid (1:9) for overnight before staining was found to be essential.

Observations were made and figures drawn at a table magnification of approximately $\times 1400$ using a Leitz compensating eye-piece of $\times 12.5$ in combination with an apochromatic objective 1.3 and an aplanatic condenser of 1.4 N.A. In the figures, chromosomes with secondary constrictions were drawn in outlines only. 


\section{Observations}

The somatic chromosome numbers of the different species and varieties of Bauhinia, Phanera and Piliostigma so far investigated have been found to range from $2 n=16$ to $2 n=28$. A number of nuclei have been found to possess varying numbers of chromosomes, other than the normal number, in the same tissue containing the normal number, in several species. The normal number in such cases had to be determined from frequency counts and the number which has been found to be present in the highest frequency in the nuclei has been regarded as the normal one. A detailed karyotype analysis of the different species and varieties reveals a gross similarity in complements. The species can be distinguished from each other by minute differences in the details of chromosome structure, including the secondary constrictions. The chromosomes, on an average, are very short in length, in comparison to the cells, which are very large. Size difference is present, though not very marked. There is a gradual gradation from the comparatively longer to short ones. Though the chromosomes are in general short, still on the basis of their relative length they can be divided into two groups, viz., comparatively long and short. Long chromosomes are generally provided with a satellite at the end of one of the arms. Karyotypes of all the species and varieties investigated in the present paper reveal that on the basis of gross morphological features a number of chromosome types is common to all of them. A critical analysis, however, shows that minor alterations in the representatives of the types are met with in different species which may be considered as criteria for the identification of these species. A significant coincidence in the total amount of chromatin matter of all the species and varieties is observed. The general types will be described separately in the beginning and their finer differences will be dealt with under karyotype description for each species. The main types which have been noted are as follows:

Type A-Long chromosome with nearly median to median primary constriction and a satellite at the distal end of the slightly short arm.

Type B-Short chromosome with nearly median to median primary constriction.

The different species differ in having different numbers of the above types. A detailed karyotype analysis of different species and varieties is dealt with separately in the following text.

Meiotic studies show very large P.M.C.'s with heavy cytoplasmic content and very small chromosomes. During meiosis, diakinesis and metaphase I reveal 14 bivalents except in Bauhinia diphylla, B. hookeri, B. rufescence, B. retusa, Phanera integrifolia and Piliostigma malabaricum. The irregularities noted in some of the species are lagging, early separation, inversion bridge, restitution nucleus, nondisjunction, secondary association, polyspory and accumulation of chromatin matter in the form of nuclei ranging in size and number from a few to many. 


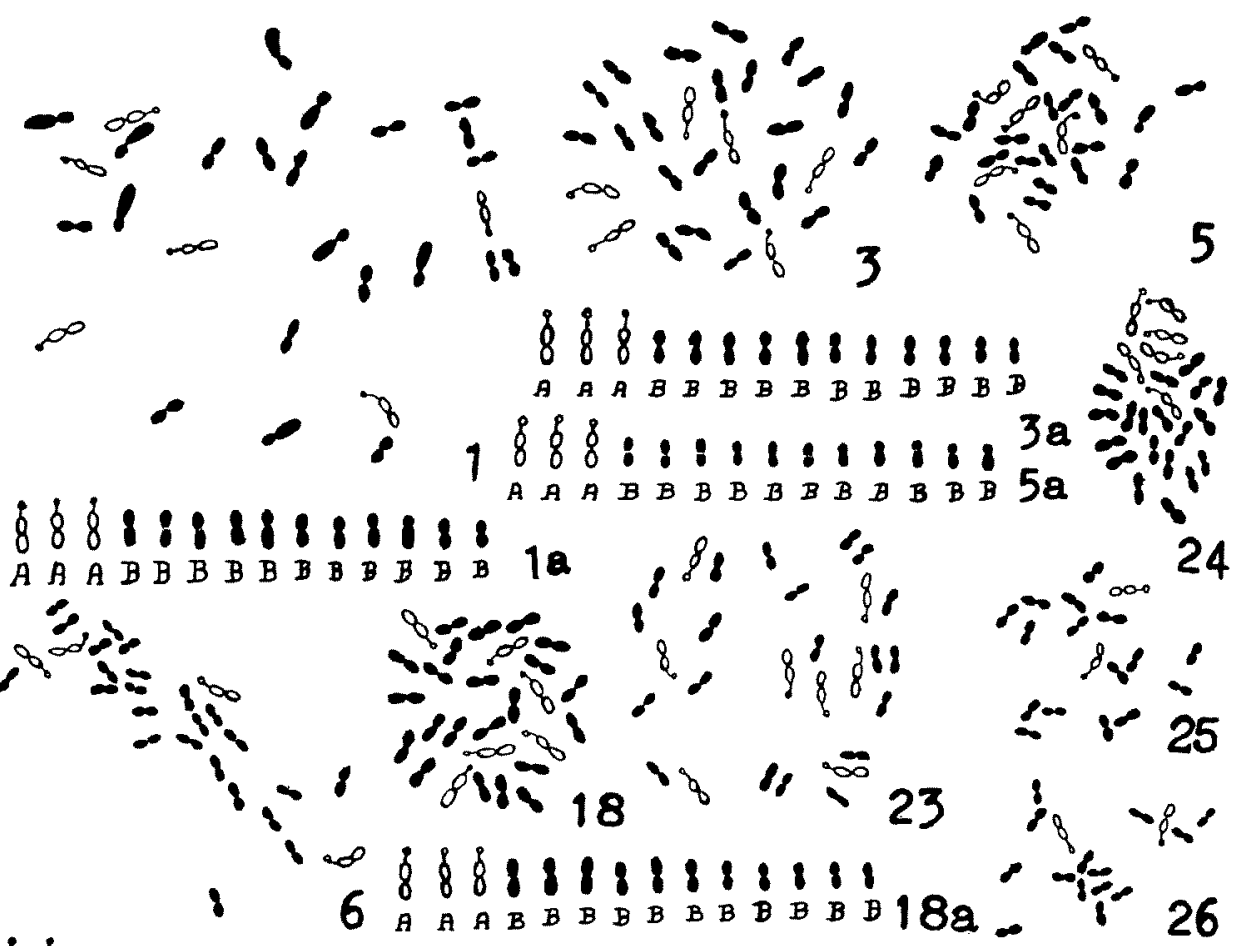

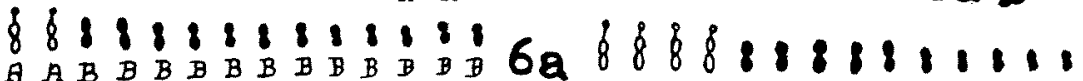

$A A B B B$ B $B$ B B B B

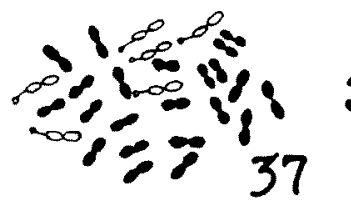

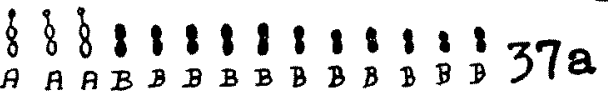

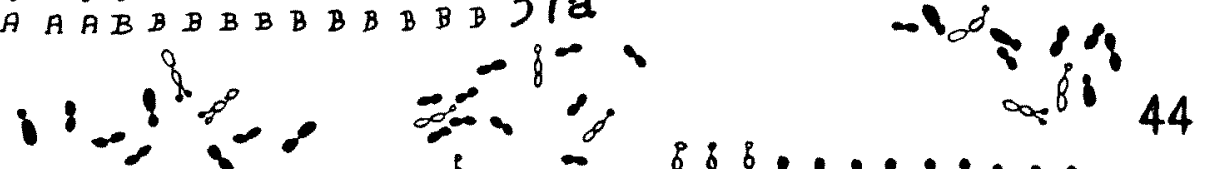

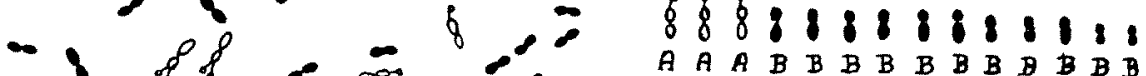

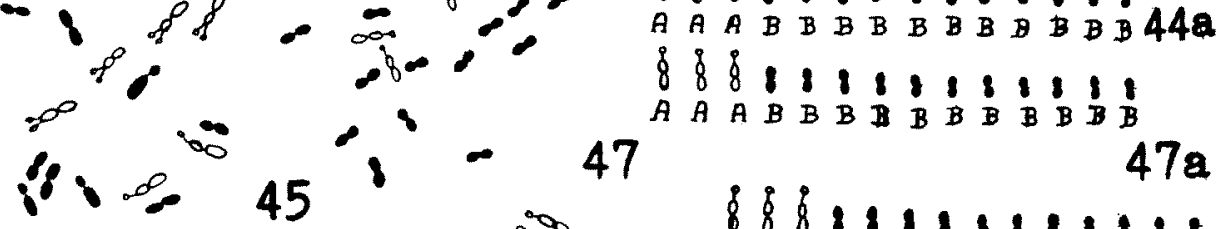

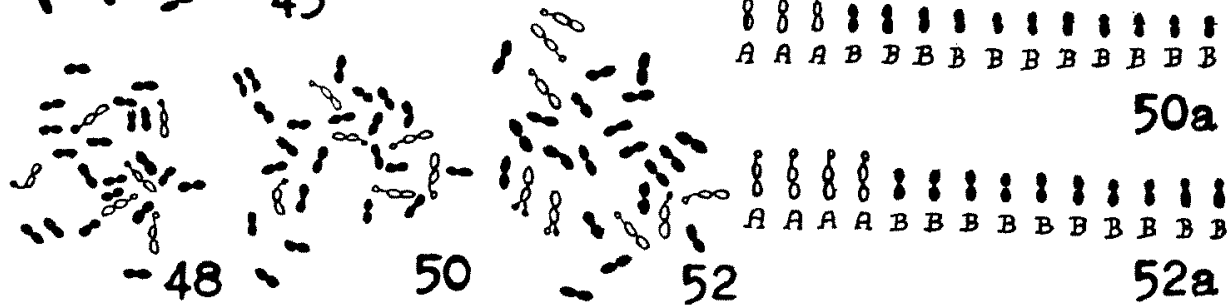

Figs. 1. 1, 1a, 3, 3a, 5, 5a, 6, 6a, 18, 18a, 23, 23a, 37, 37a, 42, 42a, 44, 44a, 47, 47a, 50, $50 \mathrm{a}$, and 52,52a. Normal somatic metaphase plates and idiograms of Bauhinia acuminata, $B$. blakeana, B. corniculata, B. diphylla, B. galpini, B. hookeai, B. monandra (Type 1), $B$. monandra (=B. krugii, Type II), B. petersiana, $B$. purpurea, $B$. purpurea var. purpurea and $B$. racemosa respectively. $24-26,45$ and 48 . Variation somatic metaphase plates of $B$. hookeri, B. petersiana and $B$. purpurea. 
1. Bauhinia aouminata Linn. $2 \mathrm{n}=28=\mathrm{A}_{6}+\mathrm{B}_{22}=1.8 \mu$ to $2.9 \mu$ (Figs. 1 to 1 a).

Meiotic studies show large P.M.C.'s with regular fourteen bivalents (Fig. 2).

2. B. blakeana Dunn. $2 \mathrm{n}=28=\mathrm{A}_{6}+\mathrm{B}_{22}=1.8 \mu$ to $3.2 \mu$ (Figs. 3 and $3 \mathrm{a}$ ).

Meiotic studies show large P.M.C.'s with regular normal fourteen bivalents (Fig. 4). Meiotic irregularities show cells with extra chromosomal droplets of stainable bodies along with the bivalents ranging both in size and number from one to numerous.

3. B. corniculata Benth. $2 \mathrm{n}=28=\mathrm{A}_{6}+\mathrm{B}_{22}=1.4 \mu$ to $3.1 \mu$ (Figs. 5 and $5 a)$.

4. B. diphylla Buch. $2 \mathrm{n}=28=\mathrm{A}_{4}+\mathrm{B}_{34}=1.4 \mu$ to $2.5 \mu$ (Figs. 6 and $6 \mathrm{a}$ ).

Meiotic studies show very large P.M.C.'s with regular normal fourteen bivalents (Fig. 7), along with other variation plates with thirteen and twelve bivalents respectively (Figs. 8 and 9). Secondary association of bivalents in metaphase $I$ is observed, the maximum association or the lowest number of grouping being $1(5)+1(4)+4(1)$. The irregularities noted at metaphase II are 12-12 and 13-13 chromosomes at each pole in each mother cell respectively (Figs. 10 and 11). The other irregularities noted are restitution nucleus, inversion bridge with a fragment, non-disjunction and polyspory respectively (Figs. 12, 13, 14 and 15, 16, 17). Each polyspore contains very small to big spores in varying numbers from 6 to 13 onwards. 5. B. galpini N. E. Br. $2 \mathrm{n}=28=\mathrm{A}_{6}+\mathrm{B}_{22}=1.8 \mu$ to $3.2 \mu$ (Fig. 18 and $18 \mathrm{a}$ ).

Meiotic studies show very large P.M.C.'s, with fourteen bivalents at diakinesis and metaphase I stages (Figs. 19 and 20). Diakinesis stage shows extra chromosomal droplets of stainable bodies with one or two bivalents attached to one of it. The irregularities noted are polyspory, containing spores varying in size and number from 6 onwards in each cell (Figs. 21 and 22).

6. B. hookeri F. Muell. $2 \mathrm{n}=28=\mathrm{A}_{8}+\mathrm{B}_{20}=1.4 \mu$ to $3.2 \mu$ (Figs. 23 and 23a).

In addition to the normal karyotype represented above, variations both in number and structure of the chromosomes have also been observed. Numerical variations showing lower numbers of $2 n=26,18$ and 16 chromosomes respectively (Figs. 24, 25 and 26) have been recorded.

Meiotic studies show very large P.M.C.'s with regular normal fourteen bivalents both at diakinesis and metaphase I (Fig. 27). Numerical variations showing lower numbers of $\mathrm{n}=13,12,10,9,8,7$ and 6 bivalents respectively (Figs. 28, 29, 30, 31, 32, 33 and 34) have also been recorded. The irregularities noted are non-disjunction of 11-9 and 12-13 chromosomes at each pole of a pollen mother cells (Figs. 35 and 36 ) respectively.

7. B. monandra Kurz. Type I. $2 \mathrm{n}=28=\mathrm{A}_{3}+\mathrm{B}_{22}=1.4 \mu$ to $3.2 \mu$ (Figs. 37 and $37 a)$.

Meiotic studies show very large P.M.C.'s with regular normal fourteen 
bivalents both at diakinesis and anaphase I (Fig. 38). Metaphase II shows 14-14 chromosomes on both the poles of the mother cell (Fig. 39). The
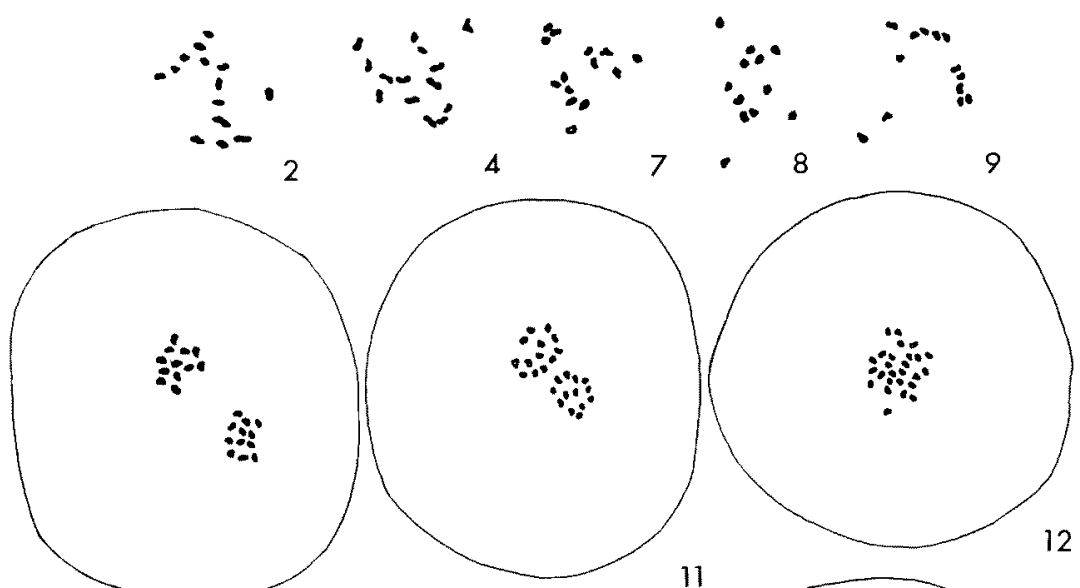

10
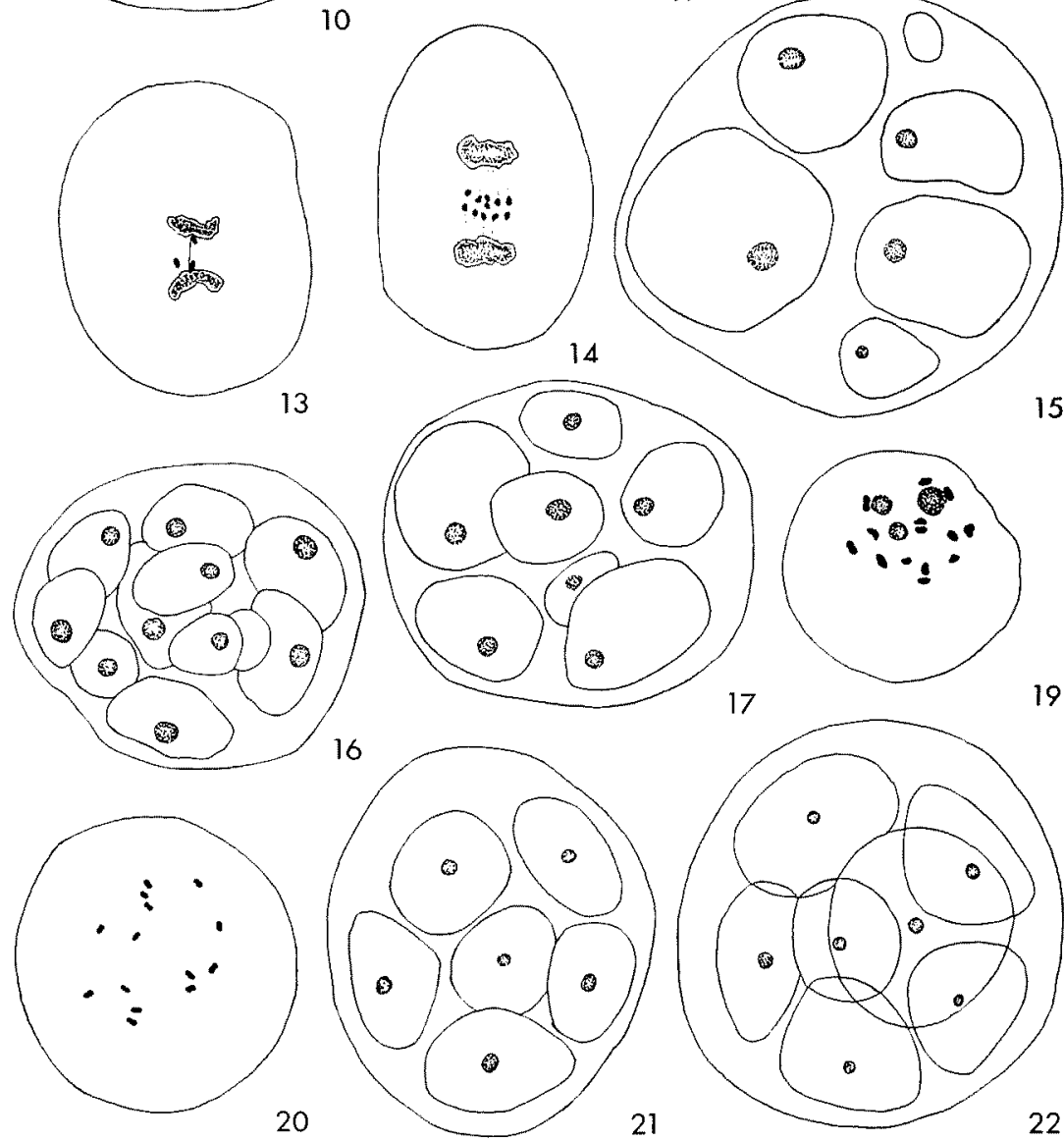

5

Figs. 2, 4, 7-17 and 19-22. Meiotic stages of B. acuminata, B. blakeana, B. diphylla and $B$. galpini respectively.

irregularity noted is polyspory, the cells containing spores of various size and number. The number of spores varies from 7-11 (Figs. 40 and 41). 
8. B. monandra Kurz. Type II (=B. krugii Urban). $2 \mathrm{n}=28=\mathrm{A}_{4}+\mathrm{B}_{24}$ $=1.4 \mu$ to $2.2 \mu$ (Figs. 42 and $42 \mathrm{a}$ ).

Meiotic studies show large P.M.C.'s with regular normal fourteen bivalents at metaphase I (Fig. 43).

9.

$B$. petersiana

C. Bolle. $2 \mathrm{n}$ $=28=\mathrm{A}_{6}+$ $\mathrm{B}_{22}=14 \mu$ to $2.9 \mu$ (Figs. 44 and $44 \mathrm{a}$ ).
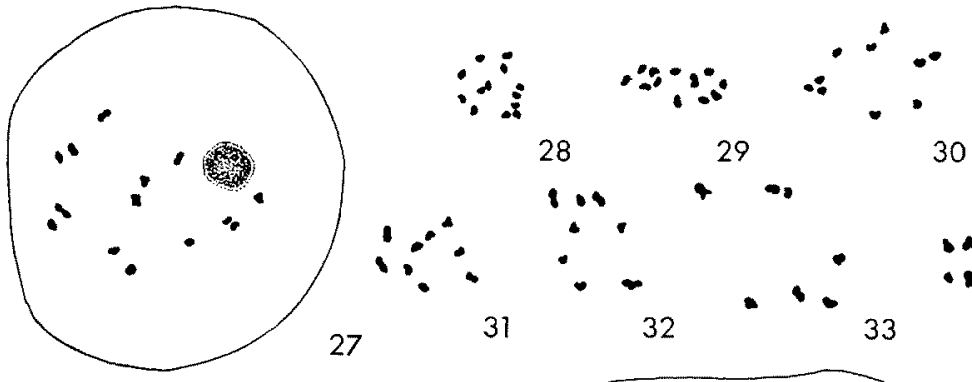

In addition to the normal

karyotype represented above, a variation nucleus with $2 \mathrm{n}=26$ chromosomes has also been recorded

(Fig. 45).

Meiotic studies show large P.M.C.'s with regular fourteen bivalents at metaphase I (Fig. 46).
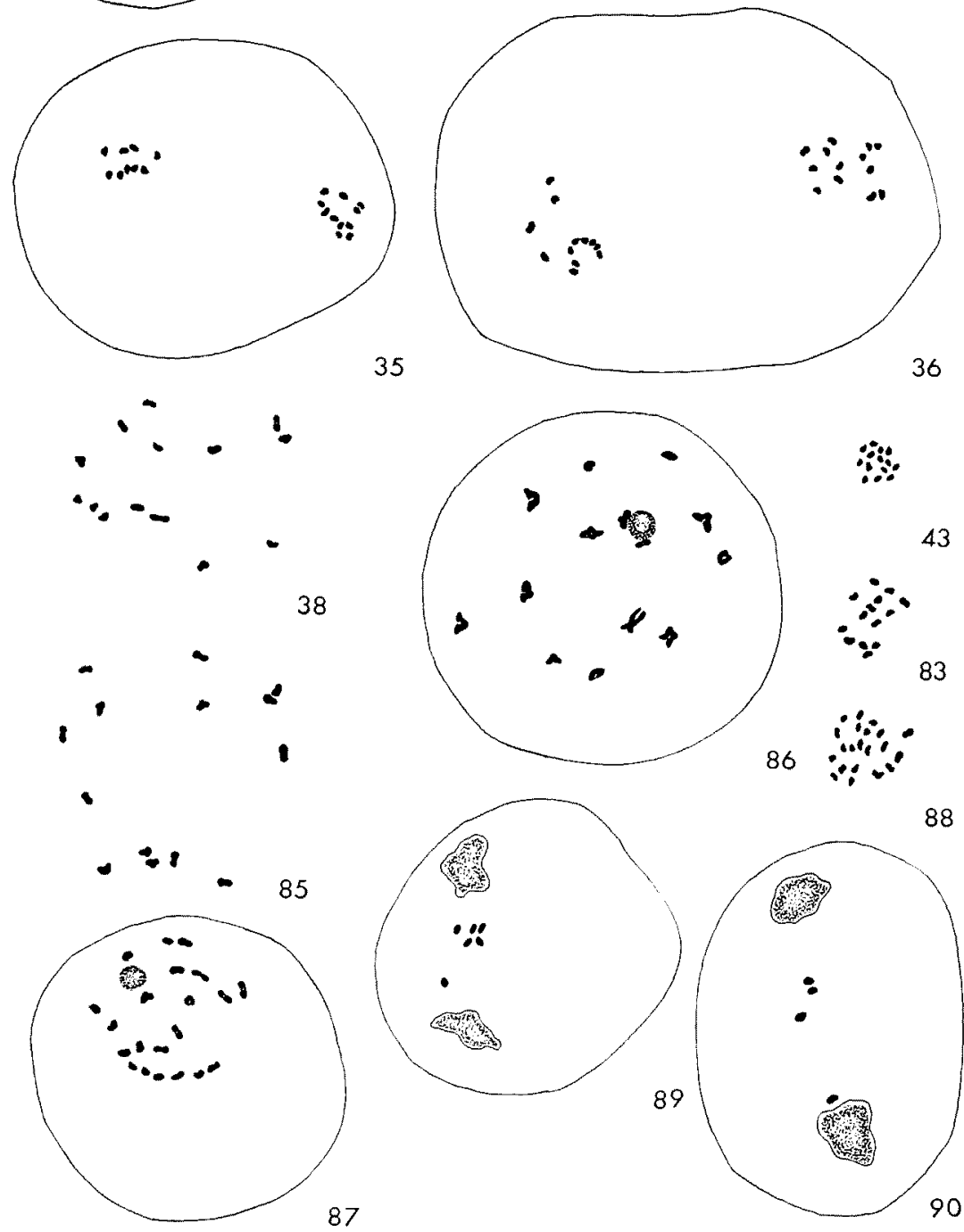

Figs. 27-36, 38, 43, 83, 85-86 and 87-90. Meiotic stages of Bauhinia hookeri, B. monandra (Type I), B. monandra (=B. krugii, Type II), Phanera semibifida $(=B$. semibifida), Piliostigma malabaricum $(=B$.

10. $B$. malabarica plant No. 1) and $P$. malabaricum (Plant No. 2) respectively. purpurea Linn. $2 \mathrm{n}=28=\mathrm{A}_{8}+\mathrm{B}_{22}=1.4 \mu$ to $2.5 \mu$ (Figs. 47 and $47 \mathrm{a}$ ). 

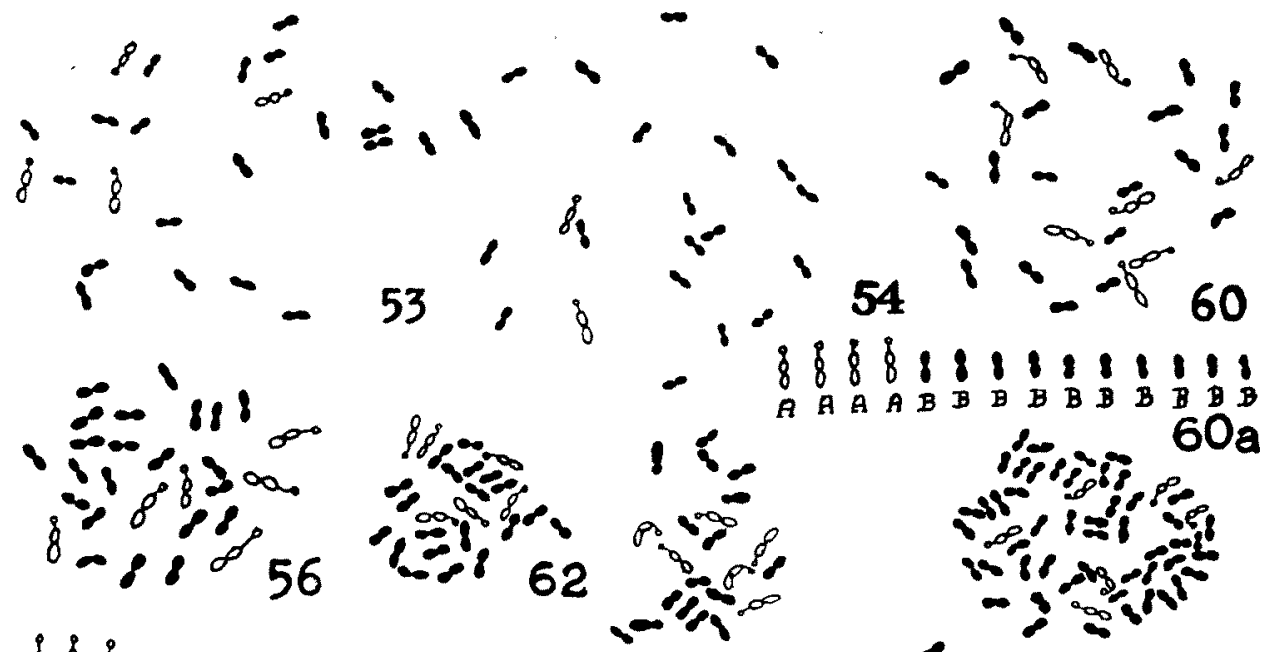

$60 a$

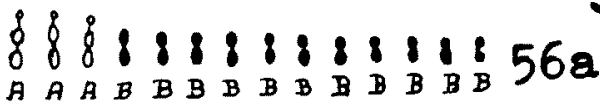
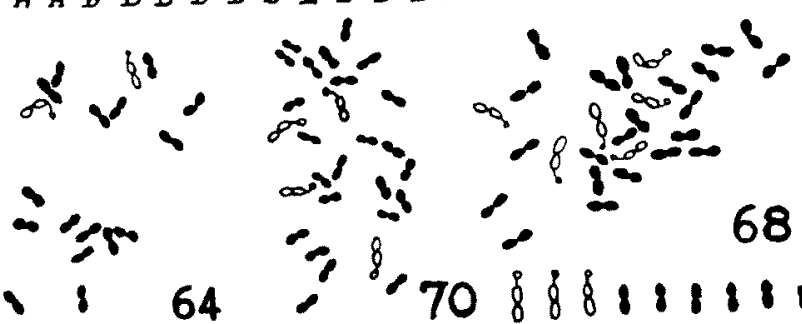

63 م 63

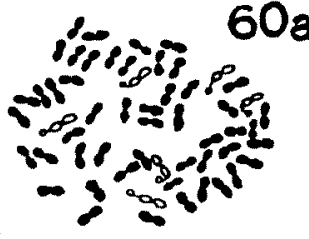

88121815111111

$A A B$ B B B B B B B B B B 70

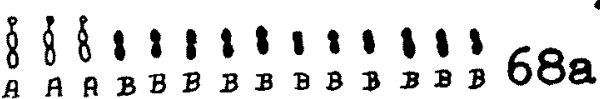

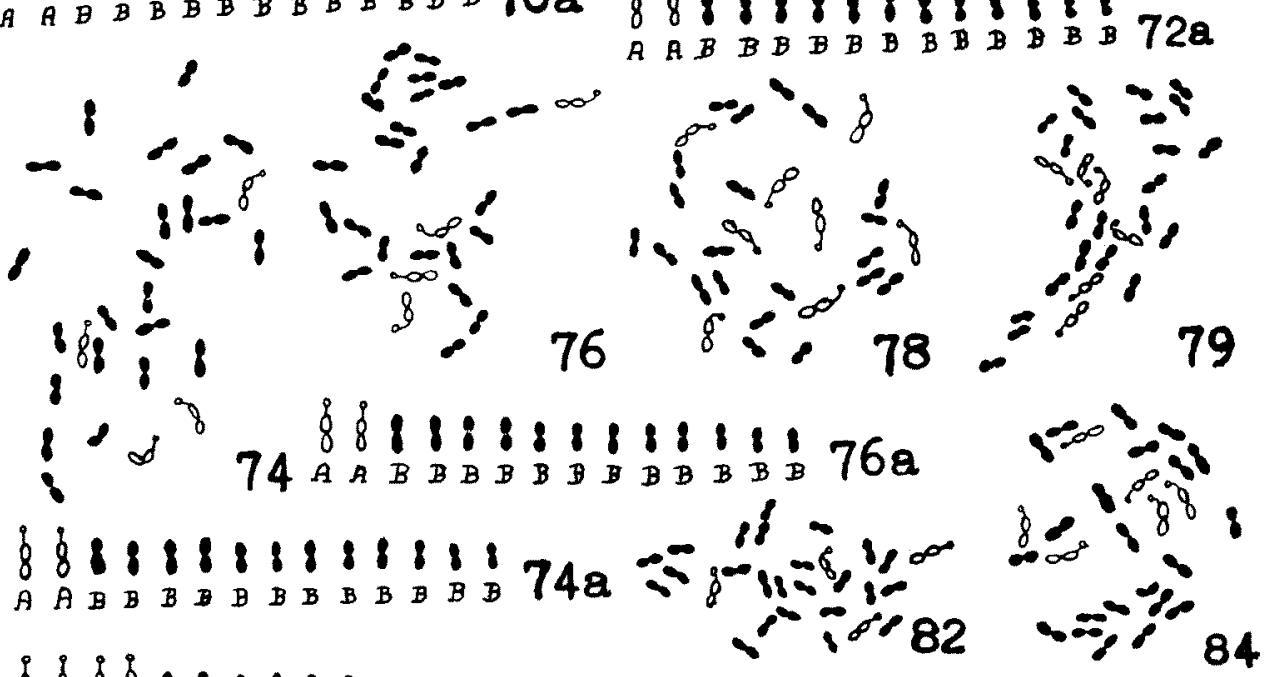

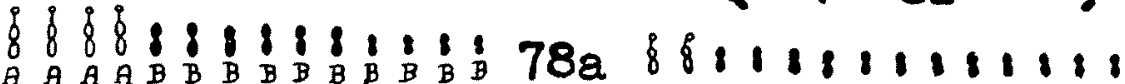

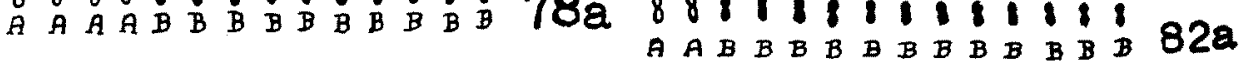

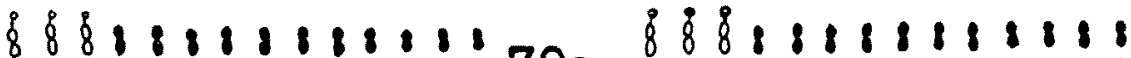

$A$ A $A$ B $B$ B

Figs. 53-54 and 61-64. Variation somatic metaphase plates of $B$. racemos $a$ and $B$. ru fescence respectively. $56,56 \mathrm{a}, 60,60 \mathrm{a}, 68,68 \mathrm{a}, 70,70 \mathrm{a}, 72,72 \mathrm{a}, 74,74 \mathrm{a}, 76,76 \mathrm{a}, 78,78 \mathrm{a}, 79,79 \mathrm{a}, 82$, $82 \mathrm{a}$ and $84,84 \mathrm{a}$. Normal somatic metaphase plates and idiograms of $B$. retusa (=Lasiobema 
In addition to the normal karyotype represented above, a variation nucleus with $2 \mathrm{n}=26$ chromosomes has also been recorded (Fig. 48).

Meiotic studies show large P.M.C.'s with regular fourteen bivalents at metaphase I (Fig. 49).

11. B. purpurea Linn. var. purpurea. $2 \mathrm{n}=28=\mathrm{A}_{\mathrm{s}}+\mathrm{B}_{2}=1.4 \mu$ to $2.9 \mu$ (Figs. 50 and 50a).

Meiotic studies show large P.M.C.'s with regular fourteen bivalents at metaphase I (Fig. 51).

12. B. racemosa Lam. $2 \mathrm{n}=28=\mathrm{A}_{8}+\mathrm{B}_{\Delta 0}=1.8 \mu$ to $2.9 \mu$ (Figs. 52 and 52a).

In addition to the normal karyotype represented above, variation nuclei containing $2 \mathrm{n}=24$ and 22 chromosomes respectively have also been noted (Figs. 53 and 54).

Meiotic studies show large P.M.C.'s with regular fourteen bivalents at metaphase I (Fig. 55).

13. B. retusa Roxb. (= Lasiobema retusum (Roxb.) de Wit, comb. nov.) $2 \mathrm{n}=28=\mathrm{A}_{6}+\mathrm{B}_{22}=1.4 \mu$ to $3.6 \mu$ (Figs. 56 and $56 \mathrm{a}$ ).

Meiotic studies show large P.M.C.'s with regular fourteen bivalents both at diakinesis and metaphase I (Fig. 57). Numerical variations showing lower numbers of 13 and 12 bivalents respectively have also been recorded (Figs. 58 and 59).

14. B. rufescence, Lam. $2 \mathrm{n}=28=\mathrm{A}_{8}+\mathrm{B}_{.0}=1.4 \mu$ to $2.9 \mu$ (Figs. 60 and 60 a).

In addition to the normal karyotype represented above, variations both in number and structure of chromosomes have also been observed. Numerical variations showing higher and lower numbers of $2 n=56,26,22$ and 18 chromosomes respectively were seen (Figs. 61, 62, 63 and 64).

Meiotic studies show large P.M.C.'s with regular fourteen bivalents both at diakinesis and metaphase I (Fig. 65). Numerical variations showing lower numbers of 11 and 9 bivalents respectively have also been recorded (Figs. 66 and 67).

15. B. tomentosa Linn. $2 \mathrm{n}=28=\mathrm{A}_{6}+\mathrm{B}_{22}=1.4 \mu$ to $2.9 \mu$ (Figs. 68 and 68a).

Meiotic studies show large P.M.C.'s with regular fourteen bivalents (Fig. 69). Meiotic irregularities show the cells with extra chromosomal droplets of stainable bodies along with bivalents present in it. These stainable bodies range from one to numerous in number and also range in size from small to big. $70 a)$.

16. B. variabilis Hort. $2 \mathrm{n}=28=\mathrm{A}_{4}+\mathrm{B}_{24}=1.4 \mu$ to $2.1 \mu$ (Figs. 70 and

Meiotic studies show large P.M.C.'s with regular fourteen bivalents at retusum), $B$. rufescence, $B$. tomentosa, $B$. variabilis, B. variegata, B. variegata var. alboflava, $B$. variegata var. variegata, Phanera corymbosa $(=B$. corymbosa), Ph. integrifolia $(=B$. vahlii), Ph. semibifida $(=B$. semibifida) and Piliostigma malabaricum $(=B$. malabarica $)$ 
metaphase I (Fig. 71).

17. B. variegata Linn. $2 \mathrm{n}=28=\mathrm{A}_{4}+\mathrm{B}_{24}=1.4 \mu$ to $2.9 \mu$ (Figs. 72 to $72 \mathrm{a}$ ).

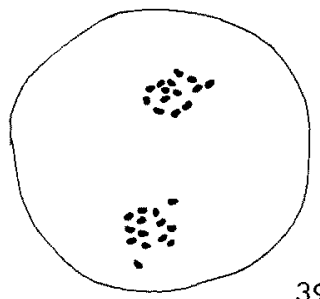

39

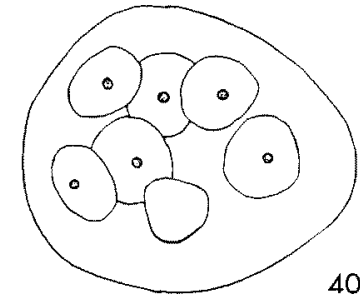

40

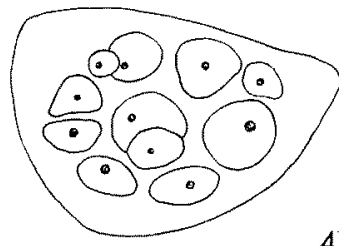

41

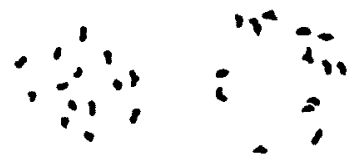

46

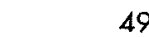

49

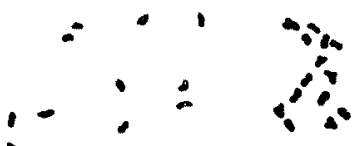

55

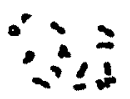
51

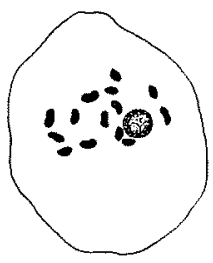

65

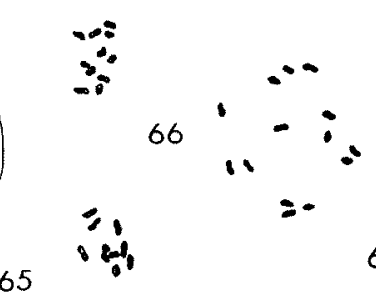

67

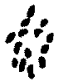

:3:

71
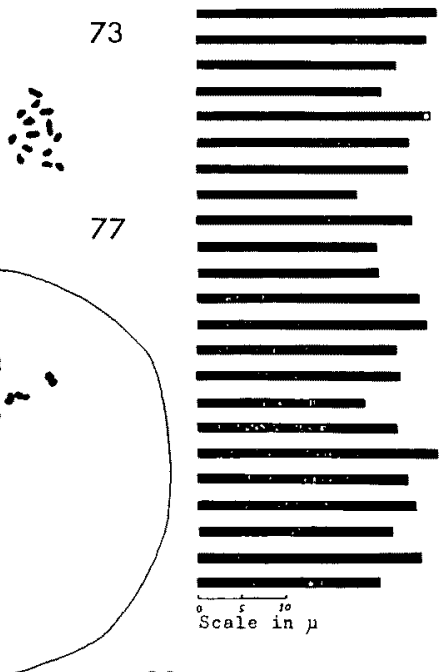

81

B. galpini

B. hooker

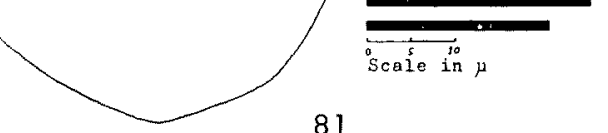

Bauhinia acuminata

B. blakeana

B. corniculata

B. diphylia

B. Monandra. Type I

B. monandra (=B.krugii). Type II

B. petersiana

B. purpurea

B. purpurea var. purpurea

B.

B. retusa (=Lasiobema retusum)

B. rufescence

B. tomentasa

B. variabilis

B. variegata

B. variegata var. alboflava

B. variegata var. variegata

Phanera corymbosa

Ph. Integrifolia

Ph. Semibifida

Piliostigma malabaricum

Figs. 39-41, 46, 49, 51, 55, 57-59, 65-67, 69, 71, 73, 75, 77 and 80-81. Meiotic stages of $B$. monandra (Type I), B. petersiana, B. purpurea, $B$. purpurea var. purpurea, $B$. racemosa, $B$. retusa (=Lasiobema retusum), $B$. rufescence, $B$. tomentosa, $B$. variabilis, $B$. variegata, $B$. variegata var. alboflava, $B$. variegata var. variegata and Phanera integrifolia ( $=B$. vahlii) respectively. 91 , histogram of different species and varieties of Bauhinia, Phanera and Piliostigma.
Meiotic studies show large P.M.C's with regular normal fourteen bivalents at metaphase I (Fig. 73).

58 18. $B$. variegata $\mathrm{L}$ var. alboflava de Wit, var. nov. $2 \mathrm{n}$ $=28=A_{4}+$ $\mathrm{B}_{24}=1.8 \mu$ to $3.2 \mu \quad$ (Figs. 74 and $74 \mathrm{a})$.

Meiotic

80 studies show large

P.M.C.'s with regular fourteen bivalents (Fig. 75).

19. B. variegata, Linn. var. rariegata. $2 \mathrm{n}=28=\mathrm{A}_{4}$ $+\mathrm{B}_{24}=1.4 \mu$ to $3.2 \mu$ (Figs. 76 to $76 \mathrm{a})$.

Meiotic studies show

large

P.M.C.'s

with regular normal four- 
teen bivalents at metaphase I (Fig. 77).

20. Phanera corymbosa (Roxb.) Benth. (=Bauhinia corymbosa Roxb.) $2 \mathrm{n}=28=\mathrm{A}_{\mathrm{s}}+\mathrm{B}_{20}=1.4 \mu$ to $2.9 \mu$ (Figs. 78 and $78 \mathrm{a}$ ).

21. Ph. integrifolia (Roxb.) Benth. $(=B$. vahlii Wight and Arn.) $2 \mathrm{n}=$ $28=\mathrm{A}_{6}+\mathrm{B}_{22}=1.4 \mu$ to $2.9 \mu$ (Figs. 79 and 79 ).

Meiotic studies show large P.M.C.'s with regular fourteen bivalents at metaphase I (Fig. 80). Numerical variation shows a lower number of 13 bivalents (Fig. 81).

22. Ph. semibifida (Roxb.) Benth. (=B. semibifida, Roxb. Hort.) $2 \mathrm{n}=28=\mathrm{A}_{4}+\mathrm{B}_{24}=1.4 \mu$ to $2.5 \mu$ (Figs. 82 and $82 \mathrm{a}$ ).

Meiotic studies show large P.M.C.'s with regular fourteen bivalents at metaphase I (Fig. 83).

23. Piliostigma malabaricum (Roxb.) Benth. (=Bauhinia malabarica Roxb., Hort.). (Plant No. I). $2 \mathrm{n}=28=\mathrm{A}_{6}+\mathrm{B}_{23}=1.8 \mu$ to $3.2 \mu$ (Figs. 84 and 84a).

Meiotic studies show very large P.M.C.'s with regular normal fourteen bivalents both at diakinesis and metaphase I (Fig. 85). Two bivalents are attached to the nucleolus at the diakinesis stage (Fig. 86).

24. P. malabaricum (Roxb.) Benth. (=B. malabarica Roxb., Hort.). (Plant No. II). Meiotic studies show large P.M.C.'s with clear small twentyone bivalents both at diakinesis and metaphase I respectively (Figs. 87 and 88). The irregularity noted is early separation (Figs. 89 and 90).

This plant was collected from a different location of the same compound, which is exactly similar in all respects with the plant number 1 of the same species from another locality.

\section{Discussion}

Chromosome studies of different species of Bauhinia, Phanera and Piliostigma so far carried out by different authors have all shown a $2 \mathrm{n}$ number of twenty-eight chromosomes, excepting Bauhinia monandra with $2 \mathrm{n}=42$ (Atchison 1951, Pantulu 1942 and Poucques 1945). During the present investigation not only the same number has been recorded in some of the species but at the same time, in no case, species have been recorded with a chromosome number which is not a multiple of 7 . This is a fair indication of the fact that these three genera represent quite a homogeneous and natural assemblage in which multiplication of chromosomes plays an important role in evolution to some extent.

In majority of the species, however, the chromosome number is constant with $2 n=28$ and chromosome morphology grossly identical in all. Therefore, the inclusion of Bauhinia, Phanera and Piliostigma under a single genus Bauhinia by Bentham and Hooker appears to be justified on the basis of cytological data.

In one species, Piliostigma malabaricum, both diploid and polyploid 
numbers have been observed. The habitat of the two species is however identical. An interesting feature about the polyploid is the formation of 21 bivalents with no multivalents. Apparently the absence of multivalents precludes the possibility of the species being an autopolyploid. But in view of the very size of the small chromosomes, which will have low chiasma frequency at the diploid level, the formation of multivalents may be checked. Possibly also, some other structural changes might have been an associated feature in evolution along with polyploidy. In that case the absence of multivalents can no doubt be explained. The other possibility is to assume an allopolyploid origin which is rather unusual in view of the very little difference in phenotypic characters of diploid and polyploid individuals. It is reasonable to assume that the polyploid observed in $P$. malabaricum is auto rather than an allopolyploid. In no other species however both auto and allopolyploid features have been observed.

The occurrence of 21 bivalents in $P$. malabaricum raises an important issue as to whether 14 or 7 chromosomes should be the basic set of the genus. In all probability it indicates 7 to represent the basic set of chromosomes. In that case all the species of these genera with twenty-eight chromosomes should be regarded as representing stable allopolyploid types, in which hybridization must have occurred at an early phase in evolution. A diploid species with 7 bivalents, probably may be available in areas where the species grows wild.

That the number 14 may be derived one, is indicated by the occasional occurrence of secondary association of bivalents in certain species, namely, Bauhinia diphylia. However, in other species no clear secondary association of bivalents has been observed. These facts clearly indicate that though the number $\mathrm{n}=14$ for Bauhinia, Phanera and Piliostigma is a secondarily derived one, yet it has become deep-seated for these genera.

Karyotype alterations and evolution of species.

The species of Bauhinia, Phanera and Piliostigma studied so far reveal very interesting data. With the aid of the special techniques improvised for somatic chromosomes of these genera, the details of karyotypes of all the species have been worked out. All species studied in general show a gross resemblance in the nature of the karyotype in rather short chromosomes with gradation in size but with no abrupt size difference in the complements. The nature of the primary constriction is nearly identical being mostly median in position. All these facts taken in conjunction with the uniformity in the chromosome number in different taxa of these genera suggest that it represents a natural assemblage.

In spite of these gross similarities, however, differences have been noticed between species in minute details, involving the number and position of the secondary constrictions. In addition, various groupings of the two principal types of the chromosomes in varying numbers are also observed. These 
facts, which could only be clarified through the common pretreatment chemicals applied for all the species, suggest the importance of minute structural alterations of chromosomes in the evolution of the different species of these genera.

The total amount of chromatin matter, as represented in the histogram (Fig. 91), reveals the close relationship in the chromatin content of all the species. On the one hand such similarity indicates the homogeneity of the taxon and on the other it suggests that structural alterations have principally involved rearrangement of parts and not deletion or duplication of segments. This has kept the general chromosome size too at a particular level. Further, karyotype alterations which otherwise maintain uniformity in chromosome size possibly have been favoured in the selection of species of these genera.

A hypothetical problem arises in view of the regular occurrence of bivalents in different species of these genera. Why, in spite of the structural alterations, is meiosis almost regular at least in majority of the species? The answer is quite simple. These genera being of horticultural importance have been continually subjected to judicious selection. Evidently prolonged evolution followed by careful selection has been responsible for the maintenance of those species only which are homozygous for such structural changes. However, other evidences of structural changes exemplified by meiotic irregularities are not uncommon in this genus. Though regular bivalent formation is the rule, non-disjunction, early separation, lagging, etc., suggest the presence of structurally altered chromosomes in the complement.

Definite evidence of such heterozygosity has been observed at least in one species where a dicentric inversion bridge with an acentric fragment has been recorded. The fate of gametes arising out of such heterozygosity is not fully known. It is likely that such inversion heterozygosity as noted in Bauhinia is principally maintained through extensive propagation by cuttings in horticulture.

Polysporous condition arising out of further mitotic division following meiosis has been observed in B. diphylla, B. galpini and B. monandra. In such polysporous types, though in all the cases the chromosome number could not be counted, the number does not seem to be identical in all the spores. Either such abnormal numbers arise through abnormalities in meiosis or in mitotic division of the tetrad nuclei. The fate of gametes arising out of this behaviour is difficult to predict. Most likely they degenerate and do not give rise to viable gametes. This is an assumption based on the fact that propagation of the species is not mainly through sexual means. Because of extensive vegetative propagation, meiotic abnormalities having no evolutionary possibilities are maintained in the plants.

In addition to the presence of 14 bivalents in the meiotic cells, P.M.C.'s have been recorded showing the occurrence of a large number of stainable bodies in the nuclei of some of the species, such as B. blakeana, B. galpini and $B$. tomentosa. It is very difficult to state at present their exact chemical 
constitution. Being carmine-positive there is the possibility of their being of nucleic acid constitution. Critical cytochemical tests are needed to work out their exact nature in terms of chemical make-up. The presence of such bodies has been reported earlier by different workers in various plant materials (Dutt 1949, Painter 1943 and Sharma 1955). Such conditions are generally met with in plants which have been subjected to environmental changes either partially or wholly. This may be the reason why they show such abnormal behaviour. In every organism a settled ratio between the two types of nucleic acid, i.e., DNA and RNA is being maintained. A breakdown of this balance is always harmful to the metabolism of the organism concerned. As under such conditions of abnormal environment, any of these two acids may be synthesized more as compared to the others. Such excess of synthesis may ultimately bring about certain disruption of normal metabolism. Plants in order to get rid of this excess of nucleic acid form extra chromosomal droplets of stainable bodies in the cell. Evidently, if it contains DNA it becomes Feulgen positive and if RNA it becomes pyronin positive. That is the reason why in certain species of plants such bodies are Feulgen positive whereas in others they are not so.

Numerical variations have been observed in the somatic tissue of a number of species, such as $B$. hookerii, B. petersiana, B. purpurea, B. racemosa and $B$. rufescence. Such numerical variations occur along with cells having normal chromosome numbers, the latter no doubt occurring in a very high frequency. In many species the variations have been found to persist even upto meiotic cells. The importance of such alterations in the somatic tissue is immense, specially in plants where propagation is through vegetative means (Sharma 1956b). Bauhinia, Phanera and Piliostigma no doubt are extensively cultivated through cuttings. But in view of the fact that none of the species so far studied shows $2 \mathrm{n}$ number other than a multiple of 14 , such aneuploid alterations in the somatic tissue probably play very little role in the origin of new races or species of these genera. Similarly, meiotic abnormalities observed in several species seem to have little significance as may possibly result in the formation of non-viable gametes. This assumption is borne out by the fact that none of the species contains an aneuploid chromosome number in the normal somatic cells.

Variations in number occurring in the somatic complement no doubt have been detected, but at the same time it is possible that structural alterations of chromosomes, if any, in cells with otherwise normal somatic numbers, might have escaped detection. This is quite likely in view of the small size of the chromosomes. Structural abnormalities occurring in low frequency may therefore have every chance of evading detection. Then the importance of structural alterations of chromosomes in the evolution of new genotype in these genera is expected through vegetative propagation. This fact needs serious consideration as species of these genera are extensively propagated by 
cutting, and at the same time differ with respect to the structure of chromosomes.

\section{Summary}

The paper deals with cytological investigations on twenty-four species and varieties of Bauhinia, Phanera and Piliostigma. Both meiotic and detailed karyotype studies were done using isopsoralene, as a pre-treatment agent. In majority of the species the chromosome number is $2 \mathrm{n}=28$ excepting $P$. malabaricum. In this species both $\mathrm{n}=14$ and 21 chromosomes have been observed. On this basis the allopolyploid nature of the polyploid forms has been suggested.

Whether 14 or 7 chromosomes should be the basic set of these genera is debatable. All chromosome numbers as yet recorded are multiples of 7 . The occasional occurrence of secondary association of bivalents in certain species, namely Bauhinia diphylla, shows that the number 14 may be a derived one.

All the species of Bauhinia, Phanera and Piliostigma show a gross similarity in the nature of karyotype, having rather short chromosomes with gradation in size. Due to the marked resemblance in karyotype, these three genera apparently represent a homogeneous assemblage and their inclusion within the same genus Bauhinia under Bentham and Hooker's system appears to be justified. Minute karyotype differences exist between different species and varieties suggesting the role of structural alteration of chromosomes in the evolution of species. Variations in chromosome number and chromosome morphology have been recorded in many species. These variations suggest that speciation and evolution in these species have been made possible through them being brought into effect through vegetative propagation. Drastic structural alterations have not been observed possibly due to the small size of the chromosomes.

The histogram reveals a similarity in the chromatin content in all the species, indicating the homogeneity of the taxa and suggesting that structural alterations have principally involved rearrangement of parts and not deletion or duplication of segments. These genera, being horticultural ones, have been continually subjected to judicious selection and homozygosity has also been attained for structural alterations.

P.M.C.'s also show a large number of extra-chromosomal droplets of stainable bodies in the cell. Being carmine-positive they may have a nucleic acid constitution. The reason for their formation through disturbance of DNA : RNA ratio has been discussed.

Definite evidences of heterozygosity namely, inversion bridge, have been observed in Bauhinia diphylla. Such inversion heterozygosity as noted in Bauhinia is principally maintained through extensive propagation by cuttings in horticulture. The possible reasons for the occurrence of polyspory and its fate have been discussed. 


\section{References}

Atchison, E. 1951. Studies in Leguminosae. VI. Chromosome numbers among tropical woody species. Amer. J. Bot. 38: 538.

Chaudhuri, M., Chakraborty, D. P. and Sharma, A. K. 1962. Isopsoralene and its use in karyotype analysis. Stain Techn. 37: 95-97.

Dutt, M. 1949. Cytogenetics of some ornamental Jasmines. Abstract, Proc. 36th Ind. Sci. Congr.

Miège, J. 1960. Nombres chromosomiques de plantes d'Afrique Occidentale. Rev. cyt. Biol. veg. 21: 373-384.

Painter, T. S. 1943. Cell growth and nucleic acids in the pollen of Rhoeo discolor. Bot. Gaz. 105: 58-68.

Pantulu, J. V. 1942. Chromosome numbers of some Caesalpiniaceae. Curr. Sci. 11: 152193.

Poucques, M. L. De 1945. Rev. Cytol., Paris, 8: 117. Taken from 'The chromosome atlas of flowering plants. By C. D. Darlington and A. P. Wylie 1955. George Allen \& Unwin Ltd., London.

Raghavan, R. S. 1957. Chromosome numbers in Indian medicinal plants. Proc. Ind. Acad. Sci. B. 45: 294-298.

Sharma, A. K. 1955. Cytology of some of the members of Commelinaceae and its bearing on the interpretation of phylogeny. Genetica 27: 323-363.

- 1956a. Fixation of plant chromosomes. Bot. Rev. 22: 665-695.

- 1956b. A new concept of a means of speciation in plants. Caryologia 9: 93-130.

Stewart, R. N. and Bamford, R. 1943. The nature of polyploidy in Lilium tigrinum. Amer. J. Bot. 30: 1-7.

Turner, B. L. 1956b. Chromosome numbers in the Leguminosae. I. Am. Jour. Bot. 43: $577-581$.

- and Irwin, H. S. 1961. Chromosome numbers of some Brazilian Leguminosae. Rhodora 63: $16-19$.

- and Fearing, O. S. 1959. Chromosome numbers in the Leguminosae. II. African species, including phyletic interpretations. Am. Jour. Bot. 46: 49-57.

Wit, H. C. D. De. 1956. A revision of Malaysian Bauhinieae. Reinwardtia 3: 381-539. 